\title{
Bcatenin is a marker of poor clinical characteristics and suppressed immune infiltration in testicular germ cell tumors
}

\author{
Michal Chovanec ${ }^{1,2,6^{*}}$ (D), Zuzana Cierna ${ }^{3}$, Viera Miskovska ${ }^{4}$, Katarina Machalekova ${ }^{5}$, Katarina Kalavska ${ }^{2,6,7}$, \\ Katarina Rejlekova ${ }^{1,2}$, Daniela Svetlovska ${ }^{2,6}$, Dusan Macak², Stanislav Spanik ${ }^{4,5}$, Karol Kajo ${ }^{5}$, Pavel Babal ${ }^{3,8}$, \\ Michal Mego $0^{1,2,6}$ and Jozef Mardiak ${ }^{1,2}$
}

\begin{abstract}
Background: WNT/Bcatenin (WNTR) pathway is activated in early stages of embryonic development. We aimed to evaluate the significance of $\beta$ catenin in germ cell tumors (GCTs) and explore associations with the inflamed environment.

Methods: Surgical specimens from 247 patients were analyzed. Bcatenin expression was detected in the tumor tissue by immunohistochemistry and correlated with clinical characteristics, outcome, PD-L1 expression and systemic immune-inflammation index (SII). The Ingenuity Pathway Analysis (IPA) was used to investigate the immune-cell related effects of $\beta$ catenin and PD-L1 encoding genes.

Results: $\beta$ catenin was expressed in $86.2 \%$ of GCTs. The expression in seminomas was significantly lower compared to all subtypes of non-seminoma (all $P<0.0001$ ). A high expression (weighted histoscore $>150$ ) was associated with primary mediastinal non-seminoma $(P=0.035)$, intermediate/poor risk disease $(P=0.033)$ and high tumor markers $(P=0.035)$. We observed a positive correlation with the PD-L1 in tumor and an inverse correlation with the SII. IPA uncovered relationships of CTNNB (Bcatenin) and CD274 (PD-L1) genes and their effects on differentiation, proliferation and activation of lymphocyte subtypes.
\end{abstract}

Conclusion: Herein, we showed that $\beta$ catenin is associated with male adult GCT characteristics as well as supressed immune environment.

Keywords: $\beta$ catenin, WNT $\beta$ pathway, PD-L1, Systemic-immune inflammation, Tumor infiltrating lymphocytes

\section{Background}

Testicular-germ cell tumors (GCTs) are chemotherapy sensitive malignancies $[1,2]$. Little was known regarding immune mechanisms in this disease until recently. The significance of PD-1/PD-L1 pathway as well as the role of systemic-immune inflammation was previously described in our works [3, 4]. Additionally, changes in cytokine signalling was observed by our team in association with poor prognosis of GCTs $[5,6]$. The role of immune check-point inhibition with anti-PD-1/anti-PD-L1/anti-CTLA4 agents

\footnotetext{
* Correspondence: michal.chovanec1@gmail.com
}

Michal Chovanec and Zuzana Cierna are co-first authors

${ }^{1}$ 2nd Department of Oncology, Faculty of Medicine, Comenius University and National Cancer Institute, Klenova 1, 83310 Bratislava, Slovak Republic

${ }^{2}$ National Cancer Institute, Klenova 1, 83310 Bratislava, Slovakia

Full list of author information is available at the end of the article has been established in numerous malignancies [7-10]. Data suggest that a T-cell inflamed microenvironment seems to be a predisposing factor for the efficacy of check-point inhibition covering only a subset of patients who benefit greatly from modern immune therapy $[11,12]$. An activation of WNT/ $\beta$ catenin (WNT $\beta$ ) signalling pathway has been recently suggested as an intrinsic inhibitory mechanism for tumor T-cell infiltration in malignant melanoma pre-clinical model [13]. WNT $\beta$ pathway is known to be activated in early stages of embryonic development and it is involved in the regulation of differentiation of pluripotent cells $[14,15]$. It has also been associated with carcinogenesis [16], cell proliferation and migration and the process of epithelial-mesenchymal transition [17]. Mutations in WNT $\beta$ have been identified in malignancies, such

(c) The Author(s). 2018 Open Access This article is distributed under the terms of the Creative Commons Attribution 4.0 International License (http://creativecommons.org/licenses/by/4.0/), which permits unrestricted use, distribution, and 
as hepatocellular, breast, colorectal and other cancer [18], however, the constitutive receptor stimulation can account for hyperactive WNT $\beta$ signalling in the absence of activating mutations as well [19]. Potapov et al. described the abundance of $\beta$ catenin in embryonal carcinoma identified by immunohistochemistry in 39 cases of testicular embryonal carcinomas [20]. Two studies reported differential expression in seminomas versus non-seminomas, but no correlation to resistance to chemotherapy was found [21, 22]. However, the role of $\beta$ catenin and WNTB signalling and its clinical implications in GCTs have not been comprehensively explored. In this retrospective study, we aimed to evaluate the role of $\beta$ catenin in GCTs and find correlations with systemic immune-inflammation and PD-L1 expression in tumor and tumor infiltrating lymphocytes (TILs).

\section{Methods}

\section{Study patients}

This translational study (chair M. Mego) included 247 patients with GCTs identified from the Slovak National Cancer Institute database, treated from January 1999 to December 2013 with available paraffin embedded tumor tissue specimen and sufficient follow-up clinical data. Patients with concurrent malignancy other than non-melanoma skin cancer in the previous 5 years were excluded. In all patients, data regarding age, tumor histology, clinical stage, type and number of metastatic sites, and delivery of systemic therapy were recorded and compared with $\beta$ catenin expression. Previously published data regarding PD-L1 expression on tumor/TILs and systemic immune-inflammation index (SII) in this cohort were available from 240 and 181 study patients, respectively $[4,23]$. The Institutional Review Board (Ethics committee of Slovak National Cancer Institute in Bratislava approved this retrospective study (version 6.1 from 15 February 2017; ref. IZLO1) and a waiver of consent form patients was granted.

\section{Tumor pathology}

Pathology review was conducted at the Department of Pathology, Faculty of Medicine, Comenius University, by two pathologists (ZC and $\mathrm{PB}$ ) associated with the study.

\section{Diagnosis and tissue samples}

Tumor tissue and normal testicular tissue were evaluated in all cases, when available. The study included tumor specimens from 247 patients before administration of systemic therapy. All but 9 of these specimens were obtained from primary testicular tumors. Biopsies of abdominal and mediastinal masses were performed in 7 and in 2 cases of primary extragonadal tumors, respectively. The GCTs were classified according to World Health Organization criteria [24]. Normal testicular tissue from non-cancer patients was not available for analysis, therefore we used normal tissue adjacent to testicular tumor for $\beta$ catenin expression evaluation, as described in previous studies $[25,26]$.

\section{Tissue microarray construction}

According to the tumor histology, one or two representative tumor areas from each histological subtype (1-6 cores from each tumor) of germ cell tumor were identified on $\mathrm{H} \& \mathrm{E}$ sections. In case of mixed germ cell tumors, selected GCT histologies were sampled to isolate a specific histological pattern. Samples from normal testicular tissue were also marked, if present. Sections were matched to their corresponding wax blocks (the donor blocks), and 3-mm diameter cores of the tissues were removed from these donor blocks with the multipurpose sampling tool Harris Uni-Core (Sigma-Aldrich, Steinheim, Germany) and inserted into the recipient master block. The recipient block was cut into 5 - $\mu \mathrm{m}$ sections and sections were transferred to coated slides. Tissue microarray construction and immunohistochemical staining was described in detail previously [4].

\section{Immunohistochemical staining}

Slides were deparaffinized and rehydrated in phosphate buffered saline solution (10 mM, pH 7.2). The tissue epitopes were demasked using the automated water bath heating process in Dako PT Link (Dako, Glostrup, Denmark); the slides were incubated in TRIS-EDTA retrieval solution (10 mM TRIS, $1 \mathrm{mM}$ EDTA pH 9.0) at $98{ }^{\circ} \mathrm{C}$ for $20 \mathrm{~min}$. The slides were subsequently incubated for $1 \mathrm{~h}$ at room temperature with the primary mouse monoclonal antibody against Beta-Catenin (Dako, $\beta$-Catenin-1, IR702, Ready-to-Use) and immunostained using anti-mouse/anti-rabbit immuno-peroxidase polymer (EnVision FLEX/HRP, Dako, Glostrup, Denmark) for $30 \mathrm{~min}$ at room temperature, according to the manufacturer's instructions. For visualization, the slides were reacted with diaminobenzidine substrate-chromogen solution (DAB, Dako, Glostrup, Denmark) for $5 \mathrm{~min}$. Finally, the slides were counterstained with haematoxylin. Bcatenin positivity of epithelial cells in the colon was used as a positive control, same tissue with omitting of the primary antibody served as negative control.

\section{Immunohistochemical stain scoring}

Tumor cores were independently assessed by two observers ( $\mathrm{ZC}$ and $\mathrm{PB}$ ) who were blinded to the clinicopathological data. In cases of disagreement, the consensus was made. Tumor cells with $\beta$ catenin expression were scored by a weighted histoscore (HS) which accounts for both the extent of cell staining and the staining intensity [27]. The portion of positive cells was estimated on a scale from 0 to $100 \%$. The average 
intensity of positively staining cells was given a score from 0 to $3(0=$ no staining; 1 = weak; 2 = intermediate; and $3=$ strong staining). The HS was then calculated by multiplying the percentage score by the intensity score, to yield a minimum value of 0 and a maximum value of 300 . Based on the HS, a $\beta$ catenin expression was graded as low (0-150) or high (160-300) as we described previously [25]. If multiple histologic subtypes were present in a sample, we chose the highest number among these for a final $\beta$ catenin expression of a mixed GCT.

\section{Systemic immune-inflammation index}

The SII is an index based on platelets (P), neutrophils $(\mathrm{N})$ and lymphocytes (L) counts from the complete blood count. It was calculated as: $\mathrm{SII}=\mathrm{P} \times \mathrm{N} / \mathrm{L}$ as defined previously [28]. The median value (1003) obtained and validated in our previous study [23] was used as the cut-off value of SII, which was then dichotomized into low (below median) and high (above median) categories.

\section{Ingenuity pathway analysis (IPA)}

We used IPA to further explore the immune related effects and interactions of CTNNB1 (the gene encoding ßcatenin) and CD274 (the gene encoding PD-L1). CTNNB1 and CD274 genes were entered into IPA search engine. Immune related effects were subsequently selected and interactions between CTNNB1, CD274 and the selected effects were assessed to create the network of interactions.

\section{Statistical analysis}

Patients' characteristics were tabulated. A distribution of $\beta$ catenin HS was significantly different from the normal distribution (Shapiro-Wilk test), therefore we used non-parametric tests for analyses. Analyses of differences in distributions of $\beta$ catenin expression between the two groups of patients were performed using the MannWhitney $U$ test, while Fisher's exact test or the $\chi^{2}$ test when appropriate were used, when $\beta$ catenin expression was categorized as 'low' or 'high'. A one-way analysis of variance and a Chi-square test were used for analyses of associations between the $\beta$ catenin and SII or PD-L1 expression.

A median follow-up period was calculated as a median observation time among all patients and among those still alive at the time of their last follow-up. PFS was calculated from the date of orchiectomy or the date of tumor biopsy to the date of progression or death or the date of the last adequate follow-up. OS was calculated from the date of orchiectomy or the date of tumor biopsy to the date of death or last the follow-up. PFS and OS were estimated using the Kaplan-Meier product limit method and compared by the log-rank test. All reported $P$ values were two sided. A $P$ value $<0.05$ was considered as significant. Statistical analyses were performed using NCSS 2007 software (Hintze J, 2007, Kaysville, Utah, USA).

\section{Results}

Patients' characteristics are shown in Table 1. Majority of patients had a non-seminoma histology. A testicular tumor was the most common primary and more than two thirds of patients were within good risk according to the IGCCCG (International Germ Cell Cancer Collaborative Group). Tumor specimens from 247 patients before administration of systemic therapy included 50 pure seminomas, 128 non-seminomas (86 embryonal carcinomas, 19 yolk sac tumors, 1 choriocarcinoma, 22 teratomas) and 69 mixed GCTs. (Additional file 1: Table S1). Eight cases of seminomas were clinically considered as non-seminomas based on the positivity of alpha-fetoprotein.

Table 1 Patients' characteristics

\begin{tabular}{|c|c|c|}
\hline & $N=247$ & $\%$ \\
\hline \multicolumn{3}{|l|}{ Age (years) } \\
\hline Median (range) & $30(17-67)$ & \\
\hline \multicolumn{3}{|l|}{ Histology } \\
\hline Pure seminoma & 50 & 20.2 \\
\hline Non-seminoma or mixed GCT & 197 & 79.8 \\
\hline \multicolumn{3}{|l|}{ Primary tumor } \\
\hline Gonadal & 238 & 96.4 \\
\hline Primary retroperitoneal & 7 & 2.8 \\
\hline Primary mediastinal & 2 & 0.9 \\
\hline \multicolumn{3}{|l|}{ IGCCCG risk group } \\
\hline Good risk & 184 & 74.5 \\
\hline Intermediate risk & 29 & 11.7 \\
\hline Poor risk & 34 & 13.8 \\
\hline \multicolumn{3}{|l|}{ Sites of metastases } \\
\hline Retroperitoneum & 175 & 70.9 \\
\hline Mediastinum & 32 & 13.0 \\
\hline Lungs & 60 & 24.3 \\
\hline Liver & 18 & 7.3 \\
\hline Other & 34 & 13.8 \\
\hline Non-pulmonary visceral metastases & 22 & 8.9 \\
\hline \multicolumn{3}{|l|}{ No. of metastatic sites } \\
\hline 0 & 63 & 25.5 \\
\hline $1-2$ & 141 & 57.1 \\
\hline$>3$ & 43 & 17.4 \\
\hline \multicolumn{3}{|l|}{ Mean (range) of pre-treatment markers } \\
\hline AFP $\mathrm{mlU} / \mathrm{ml}$ & $1274(0-60,570)$ & \\
\hline$\beta-H C G I U / m l$ & $10,412(0-423,338)$ & \\
\hline LDH (mkat/l) & $12(2-89)$ & \\
\hline
\end{tabular}




\section{Distribution of the $\beta$ catenin expression among histological subtypes}

$\beta$ catenin expression was found in specimens from 213 of 247 patients (86.2\%) in this cohort. We observed membranous staining only, cytoplasmic or nuclear staining was not present. Significantly more non-seminomas/mixed GCTs (97.3\%) showed positive staining for $\beta$ catenin compared to seminomas (51.8\%), $(P<0.0001$, Fisher's exact test). The expression in all seminomas (including pure seminomas and components in mixed tumors) was low or none (median $=5$; interquartile range 50) while non-seminomas have generally shown a stronger expression $($ median $=200$; interquartile range 100), $(P<0.0001)$. Detailed expression in all subtypes is shown in Table 2 and Additional file 2: Figure S1.

All histological subtypes of non-seminoma showed any intensity in staining more frequently than seminomas (embryonal carcinoma 98.5\%, teratoma $81.1 \%$, yolk sac tumor $96.8 \%$, choriocarcinoma $76.9 \%),(P<0.0001$ for EC, T, YST and $P=0.074$ for $\mathrm{CHC}$ ), (Fig. 1). Proportion of patients with high $\beta$ catenin expression $(H S>150)$ was significantly higher in GCNIS, YST and EC and lower in seminoma compared to adjacent normal testicular tissue (Table 2).

\section{Bcatenin and patients' characteristics}

$\beta$ catenin has shown significant associations with several clinical characteristics of patients in this cohort. Patients with testicular and retroperitoneal primary GCT had lower expression of $\beta$ catenin compared to patients with primary mediastinal non-seminoma (PMNSGCT) $\quad(P=0.035) \quad$ (Table 3). Bcatenin was higher among intermediate and poor IGCCCG risk groups as opposed to good risk patients $(P=0.033)$. Similarly, the higher expression was seen in patients with highly elevated tumor markers (S2-3) compared to patients with no or mild marker elevation (S0-1) $(P=0.035)$. Metastatic sites were generally not associated with differences in the $\beta$ catenin expression (Table 3).

\section{Bcatenin and patient outcome}

A survival analysis did not show differences among patients expressing high versus low amounts of $\beta$ catenin prior to treatment for PFS and OS; (HR 0.70, 95\% CI $0.41-1.19, P=0.185$ ) and (HR 0.89, 95\% CI 0.45-1.74, $P$ $=0.727$ ), respectively (Additional file 3: Figure S2). Sub-analyses for survival in patients with seminoma and non-seminoma also did not show statistical differences for PFS and OS (data not shown). In the subsequent analyses, we assessed the $\beta$ catenin and its' correlations with PD-L1 expression and the SII, which were previously assessed in the same patient cohort $[3,4,23]$.

\section{The association with PD-L1 on tumor cells, TILs and SII}

The expression of PD-L1 on tumor cells have shown a significant correlation with the expression of $\beta$ catenin. The expression of PD-L1 was originally reported in our previous studies [3, 4]. Samples from 240 patients were previously examined for PD-L1 and currently for the expression of $\beta$ catenin. Patients with low $\beta$ catenin had lower expression of PD-L1 on tumor cells compared to patients with the high $\beta$ catenin (median $=40$ vs 67.5 , respectively; $P=0.010$ ). Spearman's correlation analysis confirmed the significant correlation between PD-L1 on tumor cells and $\beta$ catenin $(r=0.316 ; P=0.0002)$. The PD-L1 expression on TILs did not significantly differ among patients with low $($ median $=100)$ vs high (median $=60)$ expression of $\beta$ catenin $(P=0.220)$.

$\beta$ catenin was significantly higher in patients with low SII $($ median $=200)$ vs high SII $($ median $=100)(P=0.011)$.

\section{Bcatenin and the infiltration with TILs}

We have performed an analysis to explore the association of $\beta$ catenin and the presence of TILs in tumor specimen of patients from our previous study [4]. Samples from 240 patients were previously examined for TILs and currently for the expression of $\beta$ catenin. Of 240 evaluated patients, 225 (93.7\%) had their tumor infiltrated with TILs. In our cohort, patients with no TILs did not have significantly higher expression of $\beta$ catenin

Table 2 ßcatenin expression in different histologic subtypes of germ cell tumors

\begin{tabular}{|c|c|c|c|c|c|c|c|c|c|}
\hline \multirow[t]{3}{*}{ Histologic subtype } & \multirow{3}{*}{$\mathrm{N}$} & \multirow{3}{*}{ Median } & \multicolumn{7}{|c|}{ Expression of $\beta$ catenin } \\
\hline & & & \multirow[t]{2}{*}{ Interquartile range } & \multirow[t]{2}{*}{$p$-value } & \multicolumn{2}{|c|}{ Low } & \multicolumn{2}{|c|}{ High } & \multirow[t]{2}{*}{$p$-value } \\
\hline & & & & & $\mathrm{N}$ & $\%$ & $\mathrm{~N}$ & $\%$ & \\
\hline Seminoma & 83 & 5 & 50 & NA & 81 & 97.6 & 2 & 2.4 & NA \\
\hline GCNIS & 73 & 200 & 100 & $<0.001$ & 35 & 48.0 & 38 & 52.9 & $<0.001$ \\
\hline Embryonal carcinoma & 134 & 200 & 100 & $<0.001$ & 63 & 47.0 & 71 & 53.0 & $<0.001$ \\
\hline Yolk sac tumor & 31 & 200 & 0 & $<0.001$ & 7 & 22.6 & 24 & 77.4 & $<0.001$ \\
\hline Choriocarcinoma & 13 & 100 & 165 & $<0.001$ & 7 & 53.8 & 6 & 46.2 & $<0.001$ \\
\hline Teratoma & 58 & 100 & 173 & $<0.001$ & 32 & 55.2 & 26 & 44.8 & $<0.001$ \\
\hline
\end{tabular}




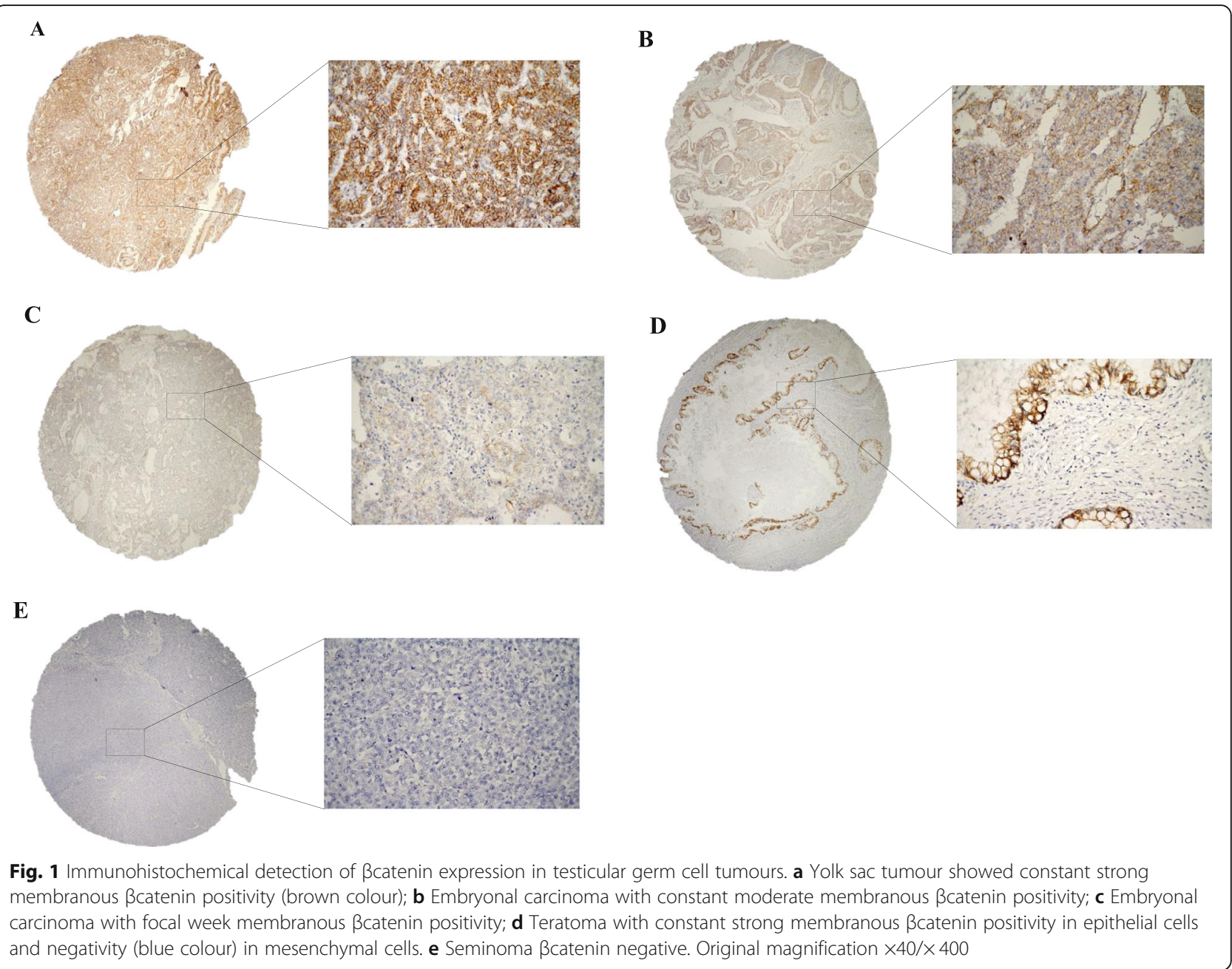

compared to patients with TILs present in the specimen (median $=200$ vs 100 , respectively; $P=0.083$ ).

\section{IPA}

We have discovered several effects of aberrant CTNNB1 and CD274 (upregulations, mutations or interactions) related to differentiation, proliferation and activation of $\mathrm{CD} 4+$ and CD8+ lymphocytes. The results of the IPA are summarized in Fig. 2.

\section{Discussion}

In this translational study, we assessed the significance of the $\beta$ catenin expression in patients with GCT prior to administration of chemotherapy. We performed a survival analysis and correlated its' expression to clinical and pathological characteristics. We identified a significant difference in the expression of $\beta$ catenin between seminomas and non-seminomas. A study by Fritsch et al. reported activated WNT $\beta$ and differential $\beta$ catenin expression in female paediatric GCT patients [29]. All non-seminoma subtypes in our study have shown strong staining for $\beta$ catenin with the highest expressions seen in embryonal carcinoma and yolk sac tumor. This finding can be attributed to the pluripotency of embryonal cancer cells that are known to be malignant counterparts of embryonic stem cells and act as stem cells in the development of GCTs. However, the implication for yolk sac tumor is unclear [30, 31]. Raggioli et al. demonstrated that $\beta$ catenin was vital for the maintenance of pluripotency associated genes in mouse embryonic stem cell lines. In addition, removal of $\beta$ catenin led to a strong increase of cell death [32]. Our study suggests the loss of $\beta$ catenin during the development from the progenitor cell, as only a weak or no expression was seen in seminomas. We hypothesize it can be responsible for different biology and treatment sensitivity compared to non-seminoma GCTs. The loss of other markers of pluripotency, such as SOX2 and CD30 was well described in the past [33]. Our further analysis uncovered differences in $\beta$ catenin expression in association with poor-risk clinical features. Primary testicular and retroperitoneal tumors had lower expression of $\beta$ catenin in comparison with PMNSGCTs which represent the 
Table 3 Patients' characteristics according to the expression of $\beta$ catenin

\begin{tabular}{|c|c|c|c|c|c|c|c|c|c|}
\hline \multirow[t]{3}{*}{ Variable } & \multirow{3}{*}{$\mathrm{N}$} & \multirow{3}{*}{ Median } & \multicolumn{7}{|l|}{ Bcatenin } \\
\hline & & & \multirow[t]{2}{*}{ interquartile range } & \multirow[t]{2}{*}{$p$-value } & \multicolumn{2}{|l|}{ Low } & \multirow{2}{*}{$\begin{array}{l}\text { High } \\
\mathrm{N}\end{array}$} & \multicolumn{2}{|l|}{$p$-value } \\
\hline & & & & & $\mathrm{N}$ & $\%$ & & $\%$ & \\
\hline All patients & 247 & 100 & 150 & NA & 131 & 53 & 116 & 47 & \\
\hline \multicolumn{10}{|l|}{ Clinical subtype } \\
\hline Pure seminoma & 50 & 50 & 100 & $<0.0001$ & 42 & 84 & 8 & 16 & $<0.0001$ \\
\hline Non-seminoma & 197 & 200 & 115 & & 89 & 45 & 108 & 55 & \\
\hline \multicolumn{10}{|l|}{ Tumor primary } \\
\hline Testicular/retroperitoneal & 245 & 100 & 150 & 0.035 & 131 & 53 & 114 & 47 & 0.131 \\
\hline Mediastinal & 2 & 300 & N/A & & 0 & 0 & 2 & 100 & \\
\hline \multicolumn{10}{|l|}{ IGCCCG risk group } \\
\hline Good & 184 & 100 & 170 & 0.033 & 105 & 57 & 79 & 43 & 0.030 \\
\hline Intermediate/Poor & 63 & 200 & 130 & & 26 & 42 & 37 & 58 & \\
\hline \multicolumn{10}{|l|}{ Number of metastatic sites } \\
\hline 0 & 63 & 100 & 100 & 0.408 & 32 & 51 & 31 & 49 & 0.813 \\
\hline 1 to 2 & 142 & 100 & 175 & & 75 & 53 & 67 & 47 & \\
\hline$\geq 3$ & 42 & 100 & 142.5 & & 24 & 57 & 18 & 43 & \\
\hline \multicolumn{10}{|l|}{ Retroperitoneal LN metastases } \\
\hline Absent & 72 & 130 & 100 & 0.075 & 36 & 50 & 36 & 50 & 0.540 \\
\hline Present & 175 & 100 & 175 & & 95 & 54 & 80 & 46 & \\
\hline \multicolumn{10}{|l|}{ Mediastinal LN metastases } \\
\hline Absent & 215 & 100 & 150 & 0.598 & 117 & 54 & 98 & 46 & 0.260 \\
\hline Present & 32 & 200 & 168.75 & & 14 & 44 & 18 & 56 & \\
\hline \multicolumn{10}{|l|}{ Lung metastases } \\
\hline Absent & 187 & 100 & 150 & 0.967 & 98 & 52 & 89 & 48 & 0.726 \\
\hline Present & 60 & 100 & 145 & & 33 & 55 & 27 & 45 & \\
\hline \multicolumn{10}{|l|}{ Liver } \\
\hline Absent & 229 & 100 & 150 & 0.243 & 124 & 54 & 105 & 46 & 0.212 \\
\hline Present & 18 & 200 & 107.5 & & 7 & 39 & 11 & 61 & \\
\hline \multicolumn{10}{|c|}{ Non-pulmonary visceral metastases } \\
\hline Absent & 225 & 100 & 150 & 0.891 & 120 & 53 & 105 & 47 & 0.765 \\
\hline Present & 22 & 150 & 150 & & 11 & 50 & 11 & 50 & \\
\hline \multicolumn{10}{|l|}{ S - stage } \\
\hline $0-1$ & 187 & 100 & 170 & 0.035 & 107 & 57 & 80 & 43 & 0.020 \\
\hline $2-3$ & 60 & 200 & 130 & & 24 & 40 & 36 & 60 & \\
\hline
\end{tabular}

worst prognostic group of GCT patients [34]. However, this sub-analysis is underpowered due to small number of PMNSGCTs in the cohort. The underlying connection to $\beta$ catenin and WTN $\beta$ signalling suggest that patients with tumors that have higher abilities for pluripotency belong to poorer risk category and produce more tumor markers. Although $\beta$ catenin assessed in our cohort of chemotherapy naive patients did not show a prognostic significance in terms of PFS and OS, further studies assessing the $\beta \mathrm{ca}$ tenin in relapsed or platinum refractory patients are needed to explore its' clinical significance.
Our subsequent analysis evaluated $\beta$ catenin and its possible associations with the tumor immune microenvironment. Our previous works have shown prognostic significance of PD-L1 expressed on tumor cells and TILs and systemic inflammation in GCTs [3, 4, 23]. Herein we identified the positive correlation of $\beta$ catenin to PD-L1 expression on tumor cells, but not on TILs. High PD-L1 expression on TILs was linked to a better outcome, whereas high PD-L1 expression on tumor cells was predictive of poor outcome in GCTs. The role of $\beta$ catenin and its' interaction with PD-1/PD-L1 pathway 


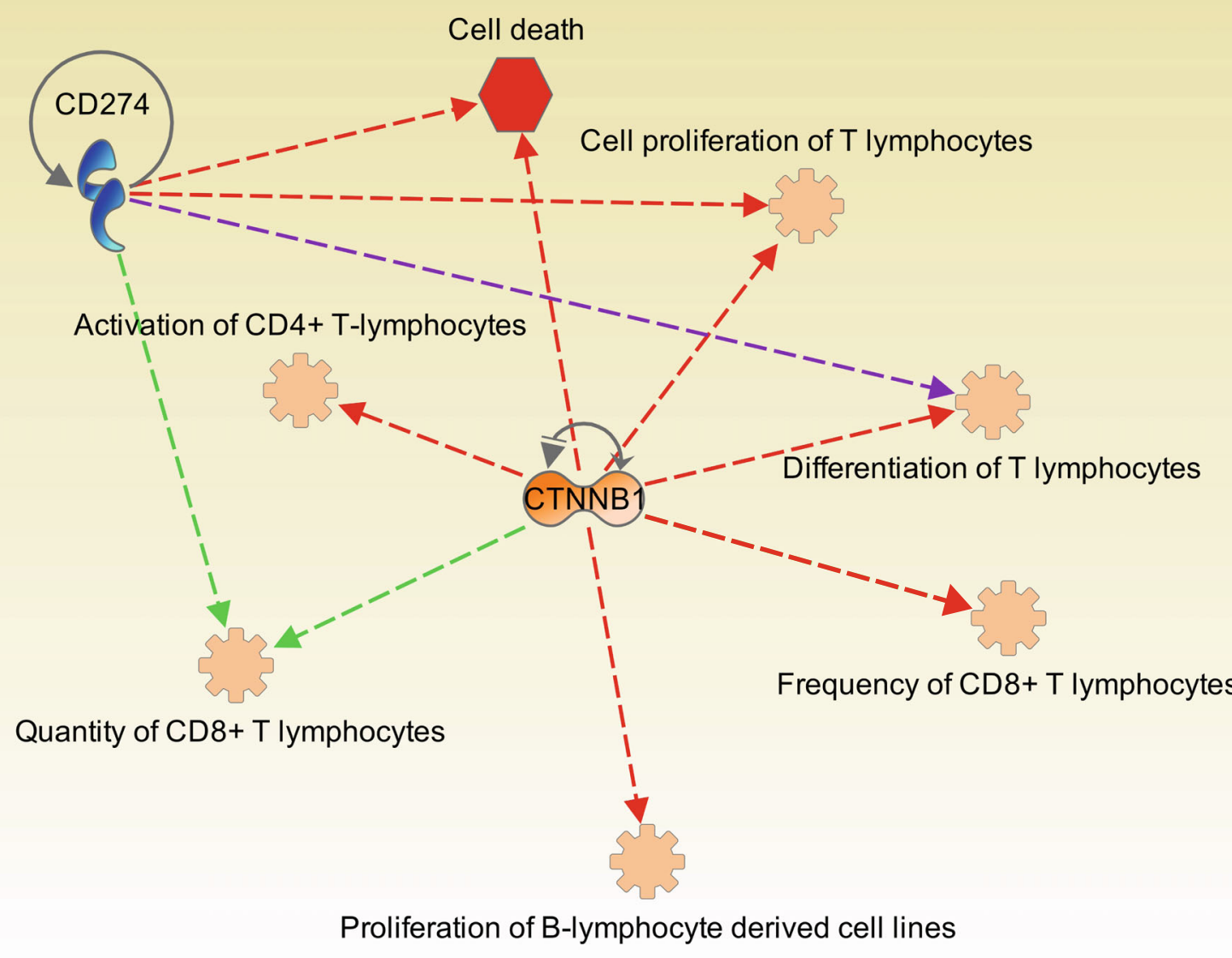

Figure legend:

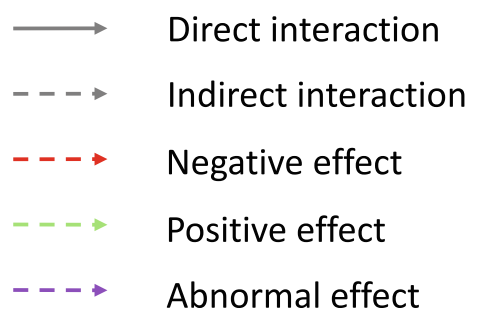

\section{CD274 - PD-L1 coding gene CTNNB1 - $\beta$ catenin coding gene}

Fig. 2 The ingenuity pathway analysis of immune-related effects of CTNNB1 and CD274. CD274 to cell death: active CD274 decreases apoptosis of cells. Inhibition of active CD274 increases apoptosis of cells. CD274 to cell proliferation of T lymphocytes: active CD274 decreases proliferation of T cells. CD274 to differentiation od T lymphocytes: mutant CD274 is involved in abnormal differentiation of T cells. CD274 to quantity of CD8+ T lymphocytes: mutant CD274 is increases number of CD8+ T cells. CTNNB1 to cell death: human CTNNB1 decreases death of cells. CTNNB1 to differentiation of T lymphocytes: active CTNNB1 increases the arrest in growth of thymocytes (thymic progenitors of T-cells). CTNNB1 to frequency of CD8+ T lymphocytes: active mutant CTNNB1 decreases differentiation thymocytes expressing CD4 and CD8 proteins. CTNNB1 to proliferation of B-lymphocyte derived cell lines: interference of CTNNB1 mRNA by siRNA decreases proliferation of pre-B cells (PD36 cells). CTNNB1 to quantity of CD8+ lymphocytes: activated mutant CTNNB1 in dendritic cells abnormally increases the number of CD8+ T cells in mouse spleen that are infected with vaccinia virus or Toxoplasma gondii. CTNNB1 to activation of CD4+ T lymphocytes: degradation of CTNNB1 protein is involved in activation of CD4+ T cells 
is not clear. Its' association with PD-L1 on tumor cells but not on TILs may suggest the independence of PD-L1 positive TILs from WNT $\beta$ signalling. Moreover, the association with immune inflamed microenvironment was confirmed in inverse correlation with SII suggesting that patients with low inflammatory activity had activated WNT $\beta$ signalling. Spranger et al. observed a lack of T-cell infiltrate in autochtonous mouse models, which led to resistance to anti-PD-L1/anti-CTLA4 monoclonal antibody therapy. Subsequently, authors were able to restore T-cell infiltration in mice by introduction of injected dendritic cells harvested from transgenic mice [13]. We did not observe a higher expression of $\beta$ catenin in patients without TILs in tumor specimens, perhaps due to insufficient size of our cohort. Our subsequent ingenuity pathway analysis uncovered important roles of CTNNB1 and CD274 genes in the process of differentiation, proliferation and function of $\mathrm{CD} 8+$ and $\mathrm{CD} 4+\mathrm{T}$ cells. The increase in number of $\mathrm{CD} 8+$ positive cells resulting from aberrant mutated CTNNB1 is seemingly conflicting with other described effects of WNT signalling, however, Cohen et al. described that these cells failed to be activated due to a lack of cross-presentation resulting from increased splenic CD8 $\alpha$ dendritic cell activity [35]. Furthermore, animal model experiments performed by Augustin et al. in mouse embryonic stem cells with overexpressed WNT secretion factor Evi/WIs, showed an increased tumor growth and impaired immune cell recruitment in the presence of enhanced Evi expression. Authors observed reduced T-cell and B-cell infiltration especially in Evi overexpressing teratomas, thus, showing the negative effect of WNT signalling on immune surveillance [36].

Our study has some strengths and limitations. The large patient population creates a relatively balanced population for the biomarker assessment. Additionally, the availability of the PD-L1 expression and the SII data from the same set of patients creates a unique cohort with the possibility to uncover associations among these. Limitations include the retrospective nature of the analysis and underrepresentation of extragonadal germ cell tumors. The membranous expression of $\beta$ catenin does not provide clear evidence of WNT pathway signalling, thus the expression of a target gene would provide more information. Our selection of $\beta$ catenin to explore as a biomarker in this hypothesis generating study may be biased, therefore we plan a more comprehensive proteomic analysis in the future.

\section{Conclusion}

In conclusion, this is the first translational study to assess the biological, prognostic and clinical significance of $\beta$ catenin in GCTs of adult men. We uncovered the differences between seminomas and non-seminomas. We have shown associations with several clinical characteristics and systemic immune-inflammation and PD-L1 on tumor cells, thus providing the insights into immunobiology of GCTs. More studies are needed to validate this exploratory trial and to explore the possible therapeutic implications.

\section{Additional files}

\section{Additional file 1: Table S1. Composition of mixed GCTs $(N=69)$. (DOCX $14 \mathrm{~kb}$ )}

Additional file 2: Figure S1. Box-plot representation of difference in the expression of $\beta$ catenin between seminoma (median $=5, I Q R=50$ ) and other histological subtypes (1); A - germ-cell neoplasia in situ (median $=200, I Q R=100) ; B$ - embryonal carcinoma (median =200, IQR =100); C yolk sac tumor (median $=200, I Q R=0)$; $D-$ choriocarcinoma (median $=100$, $I Q R=165)$; $E$ - teratoma (median =200, IQR =173). (DOCX $37 \mathrm{~kb})$

Additional file 3: Figure S2A. Kaplan-Meier estimates of probabilities of progression-free survival according to the expression of $\beta$ catenin in patients with GCTs $(n=247)$, Hazard ratio $0.70,95 \% \mathrm{Cl} 0.41-1.19)$, $P=0.185$; low $\beta$ catenin histoscore $<150$, high $\beta$ catenin histoscore $>150$ ). Figure S2B. Kaplan-Meier estimates of probabilities of overall survival according to the expression of $\beta$ catenin in patients with GCTs $(n=247)$, Hazard ratio $0.89,95 \% \mathrm{Cl} 0.45-1.74), P=0.727$; low $\beta c$ catenin histoscore $<150$, high $\beta$ catenin histoscore $>150)$. (DOCX $32 \mathrm{~kb}$ )

\section{Abbreviations}

GCT: Germ cell tumor; H\&E: Hematoxylin eosin; HS: Histoscore; IGCCC G: International Germ Cell Cancer Collaborative Group; IPA: Ingenuity pathway analysis; L: Lymphocytes; N: Neutrophils; OS: Overall survival; P: Platelets; PFS: Progression free survival; SII: Systemic immune-inflammation index; TIL: Tumor infiltrating lymphocytes

\section{Acknowledgements}

We would like to acknowledge our collaborators from departments of pathology in Slovakia: Antol M, Benko J, Danis D, Durcansky D, Fiala P, Galbavy S, Gogora M, Hudcovsky P, Macuch J, Martanovic P, Ondrias F, Plank L, Svajdler M. We would like to acknowledge Daniela Jantekova, from the Population Registry of Slovak Republic for updating patients' database, Zlatica Pekova for administration support, Alzbeta Jancikova for tissue blocks and informed consent collection, Andrea Krieschova and Simona Turnova for informed consent collection, Emilia Klincova and Ludovit Gaspar for excellent technical assistance.

\section{Funding}

This study was supported by the Slovak Research and Development Agency under contract No. APW-15-0086 and Scientific Grant Agency under contract number VEGA 1/0043/18.

\section{Availability of data and materials}

The datasets and materials used and analysed during the reported study are available at 2nd Department of Oncology and the Department of Pathology, Faculty of Medicine, Comenius University, Bratislava, Slovakia.

\section{Authors' contributions}

MC study design, patient accrual and data collection, statistical analyses, manuscript writing, revision and approval. ZC tissue immunohistochemical analysis, microscopy and pathology readings, manuscript writing, revision and approval. KM, DM, KK, PB tissue immunohistochemical analysis, microscopy and pathology readings, review and approval of the manuscript. VM, KR, SS patient accrual and data collection, manuscript revision and approval. KK data collection and management in the institutional clinical patient database, manuscript writing, revision and approval. DS informed consent collection, data management, manuscript revision and approval. MM patient accrual and data collection, statistical analyses, manuscript writing, revision and approval. JM study design, patient accrual and data collection, manuscript revision and approval. 


\section{Competing interest}

The authors declare that they have no competing interests.

\section{Ethics approval and consent to participate}

All procedures performed in this study involving human participants were in accordance with the ethical standards of the institutional and/or national research committee and with the 1964 Helsinki declaration and its later amendments or comparable ethical standards. Informed consent was obtained from all individual participants included in the study. The Institutional Review Board (Ethics committee of Slovak National Cancer Institute in Bratislava approved this retrospective study (version 6.1 from 15 February 2017; ref. IZLO1).

\section{Consent for publication}

Not applicable.

\section{Publisher's Note}

Springer Nature remains neutral with regard to jurisdictional claims in published maps and institutional affiliations.

\section{Author details}

${ }^{1}$ 2nd Department of Oncology, Faculty of Medicine, Comenius University and National Cancer Institute, Klenova 1, 83310 Bratislava, Slovak Republic. ${ }^{2}$ National Cancer Institute, Klenova 1, 83310 Bratislava, Slovakia. ${ }^{3}$ Department of Pathology, Faculty of Medicine, Comenius University, Sasinkova 4, 81108 Bratislava, Slovakia. ${ }^{4} 1$ st Department of Oncology, Faculty of Medicine, Comenius University, Kollarska 12, 81250 Bratislava, Slovakia. ${ }^{5}$ St. Elisabeth Cancer Institute, Heydukova 10, 81250 Bratislava, Slovakia. ${ }^{6}$ Translational Research Unit, Faculty of Medicine, Comenius University, Klenova 1, 83310 Bratislava, Slovakia. ${ }^{7}$ Cancer Research Institute, Slovak Academy of Sciences, Dubravska cesta 9, 84505 Bratislava, Slovakia. ${ }^{8}$ Faculty Hospital with Policlinics Skalica, a.s, Koreszkova 936/7, 90901 Skalica, Slovakia.

\section{Received: 22 March 2018 Accepted: 10 October 2018}

\section{Published online: 03 November 2018}

\section{References}

1. Einhorn LH. Treatment of testicular cancer: a new and improved model. J Clin Oncol. 1990;8(11):1777-81.

2. Mardiak J, Salek T, Sycova-Mila Z, Obertova J, Reckova M, Mego M, Hlavata Z, Brozmanova K, Risnyovzska Z, Svetlovska D, et al. Paclitaxel, bleomycin, etoposide, and cisplatin (T-BEP) as initial treatment in patients with poorprognosis germ cell tumors (GCT): a phase II study. Neoplasma. 2007;54(3): 240-5.

3. Cierna Z, Mego M, Miskovska V, Machalekova K, Chovanec M, Svetlovska D, Hainova K, Rejlekova K, Macak D, Spanik S, et al. Prognostic value of programmed-death-1 receptor (PD-1) and its ligand 1 (PD-L1) in testicular germ cell tumors. Ann Oncol. 2016;27(2):300-5.

4. Chovanec M, Cierna Z, Miskovska V, Machalekova K, Svetlovska D, Kalavska K, Rejlekova K, Spanik S, Kajo K, Babal P, et al. Prognostic role of programmeddeath ligand 1 (PD-L1) expressing tumor infiltrating lymphocytes in testicular germ cell tumors. Oncotarget. 2017;8(13):21794-805.

5. Chovanec M, Mego M, Cholujova D, Gronesova P, Miskovska V, Sycova-Mila Z, Usakova V, Svetlovska D, Bujdak P, Spanik S, et al. A cytokine and angiogenic factor (CAF) analysis in plasma in testicular germ cell tumor patients (TGCTs). J Clin Oncol. 2015;33(15):e15552.

6. Svetlovska D, Miskovska V, Cholujova D, Gronesova P, Cingelova S, Chovanec M, Sycova-Mila Z, Obertova J, Palacka P, Rajec J, et al. Plasma cytokines correlated with disease characteristic, progression free survival and overall survival in testicular germ cell tumour patients. Clin Genitourin Cancer. 2017; Article In Press.

7. Ansell SM, Lesokhin AM, Borrello I, Halwani A, Scott EC, Gutierrez M, Schuster SJ, Millenson MM, Cattry D, Freeman GJ, et al. PD-1 blockade with nivolumab in relapsed or refractory Hodgkin's lymphoma. N Engl J Med. 2015:372(4):311-9.

8. Garon EB, Rizvi NA, Hui R, Leighl N, Balmanoukian AS, Eder JP, Patnaik A, Aggarwal C, Gubens M, Horn L, et al. Pembrolizumab for the treatment of non-small-cell lung cancer. N Engl J Med. 2015;372(21):2018-28.

9. Herbst RS, Soria JC, Kowanetz M, Fine GD, Hamid O, Gordon MS, Sosman JA, McDermott DF, Powderly JD, Gettinger SN, et al. Predictive correlates of response to the anti-PD-L1 antibody MPDL3280A in cancer patients. Nature. 2014:515(7528):563-7.

10. Powles T, Eder JP, Fine GD, Braiteh FS, Loriot Y, Cruz C, Bellmunt J, Burris HA, Petrylak DP, Teng SL, et al. MPDL3280A (anti-PD-L1) treatment leads to clinical activity in metastatic bladder cancer. Nature. 2014;515(7528):558-62.

11. Harlin H, Meng Y, Peterson AC, Zha Y, Tretiakova M, Slingluff C, McKee M, Gajewski TF. Chemokine expression in melanoma metastases associated with CD8+ T-cell recruitment. Cancer Res. 2009;69(7):3077-85.

12. Ji RR, Chasalow SD, Wang L, Hamid O, Schmidt H, Cogswell J, Alaparthy S, Berman D, Jure-Kunkel M, Siemers NO, et al. An immune-active tumor microenvironment favors clinical response to ipilimumab. Cancer immunology, immunotherapy : CII. 2012;61(7):1019-31.

13. Spranger $S$, Bao R, Gajewski TF. Melanoma-intrinsic beta-catenin signalling prevents anti-tumour immunity. Nature. 2015:523(7559):231-5.

14. ten Berge D, Kurek D, Blauwkamp T, Koole W, Maas A, Eroglu E, Siu RK, Nusse R. Embryonic stem cells require Wnt proteins to prevent differentiation to epiblast stem cells. Nat Cell Biol. 2011;13(9):1070-5.

15. Ying QL, Wray J, Nichols J, Batlle-Morera L, Doble B, Woodgett J, Cohen P, Smith $A$. The ground state of embryonic stem cell self-renewal. Nature. 2008:453(7194):519-23.

16. Bhatia N, Spiegelman VS. Activation of Wnt/beta-catenin/Tcf signaling in mouse skin carcinogenesis. Mol Carcinog. 2005:42(4):213-21.

17. Eger A, Stockinger A, Schaffhauser B, Beug H, Foisner R. Epithelial mesenchymal transition by c-Fos estrogen receptor activation involves nuclear translocation of beta-catenin and upregulation of beta-catenin/ lymphoid enhancer binding factor-1 transcriptional activity. J Cell Biol. 2000 148(1):173-88.

18. Forbes SA, Bindal N, Bamford S, Cole C, Kok CY, Beare D, Jia M, Shepherd R, Leung $\mathrm{K}$, Menzies A, et al. COSMIC: mining complete cancer genomes in the catalogue of somatic mutations in Cancer. Nucleic Acids Res. 2011; 39(Database issue):D945-50.

19. Blagodatski A, Poteryaev D, Katanaev VL. Targeting the Wnt pathways for therapies. Mol Cell Ther. 2014;2:28.

20. Potapov S, Sidorenko R, Galata D, Stratiy N, Gargin V. Peculiarities of catenin activity in the embryonal testicular carcinoma. Georgian Med News. 2016; 261:68-73.

21. Honecker F, Kersemaekers AM, Molier M, Van Weeren PC, Stoop H, De Krijger RR, Wolffenbuttel KP, Oosterhuis W, Bokemeyer C, Looijenga LH. Involvement of E-cadherin and beta-catenin in germ cell tumours and in normal male fetal germ cell development. J Pathol. 2004;204(2):167-74.

22. Fernando G, Paul F, Laura J, Alejandra AM, Gabriela M, Alberto PL. Is the Wnt/beta catenin signalling pathway activated in seminoma?: An immunohistochemical study. J Cancer Res Ther. 2016;12(2):1075-9.

23. Chovanec M, Cierna Z, Miskovska V, Machalekova K, Kalavska K, Rejlekova K, Svetlovska D, Macak D, Spanik S, Kajo K, et al. Systemic immuneinflammation index in germ-cell tumours. Br J Cancer. 2018;118(6):831-8.

24. Ulbright TM, Amin MB, Balzer B, Berney DM, Epstein Jl, Gu C, Indrees MT, Looijenga LHJ, Paner G, Rajpert-De Meyts $E$, et al. Tumours of the testis and paratesticular tissue. In: Moch H, Humphrey PA, Ulbright TM, Reuter VE, editors. WHO Classification of Tumours of the Urinary System and Male Genital Organs. 4th ed. Lyon: International Agency for Research on Cancer (IARC): 2016. p. 185-258.

25. Mego M, Cierna Z, Svetlovska D, Macak D, Machalekova K, Miskovska V, Chovanec M, Usakova V, Obertova J, Babal P, et al. PARP expression in germ cell tumours. J Clin Pathol. 2013;66(7):607-12.

26. Ulisse S, Baldini E, Mottolese M, Sentinelli S, Gargiulo P, Valentina B, Sorrenti S, Di Benedetto A, De Antoni E, D'Armiento M. Increased expression of urokinase plasminogen activator and its cognate receptor in human seminomas. BMC Cancer. 2010;10:151.

27. Kirkegaard T, Edwards J, Tovey S, McGlynn LM, Krishna SN, Mukherjee R, Tam L, Munro AF, Dunne B, Bartlett JM. Observer variation in immunohistochemical analysis of protein expression, time for a change? Histopathology. 2006:48(7):787-94

28. Hu B, Yang XR, Xu Y, Sun YF, Sun C, Guo W, Zhang X, Wang WM, Qiu SJ, Zhou J, et al. Systemic immune-inflammation index predicts prognosis of patients after curative resection for hepatocellular carcinoma. Clinical Cancer Res. 2014:20(23):6212-22

29. Fritsch MK, Schneider DT, Schuster AE, Murdoch FE, Perlman EJ. Activation of Wnt/beta-catenin signaling in distinct histologic subtypes of human germ cell tumors. Pediatr Dev Pathol. 2006;9(2):115-31. 
30. Andrews PW, Matin MM, Bahrami AR, Damjanov I, Gokhale P, Draper JS. Embryonic stem (ES) cells and embryonal carcinoma (EC) cells: opposite sides of the same coin. Biochem Soc Trans. 2005;33(Pt 6):1526-30.

31. Abu Dawud R, Schreiber K, Schomburg D, Adjaye J. Human embryonic stem cells and embryonal carcinoma cells have overlapping and distinct metabolic signatures. PLoS One. 2012;7(6):e39896.

32. Raggioli A, Junghans D, Rudloff $S$, Kemler R. Beta-catenin is vital for the integrity of mouse embryonic stem cells. PLoS One. 2014;9(1):e86691.

33. de Jong J, Stoop H, Gillis AJ, Hersmus R, van Gurp RJ, van de Geijn GJ, van Drunen E, Beverloo HB, Schneider DT, Sherlock JK, et al. Further characterization of the first seminoma cell line TCam-2. Genes Chromosomes Cancer. 2008;47(3):185-96.

34. Adra N, Althouse SK, Liu H, Brames MJ, Hanna NH, Einhorn LH, Albany C. Prognostic factors in patients with poor-risk germ-cell tumors: a retrospective analysis of the Indiana University experience from 1990 to 2014. Ann Oncol. 2016;27(5):875-9.

35. Cohen SB, Smith NL, McDougal C, Pepper M, Shah S, Yap GS, Acha-Orbea H, Jiang $A$, Clausen BE, Rudd BD, et al. Beta-catenin signaling drives differentiation and proinflammatory function of IRF8-dependent dendritic cells. J Immunol. 2015;194(1):210-22.

36. Augustin I, Dewi DL, Hundshammer J, Rempel E, Brunk F, Boutros M. Immune cell recruitment in teratomas is impaired by increased Wnt secretion. Stem Cell Res. 2016;17(3):607-15.

Ready to submit your research? Choose BMC and benefit from:

- fast, convenient online submission

- thorough peer review by experienced researchers in your field

- rapid publication on acceptance

- support for research data, including large and complex data types

- gold Open Access which fosters wider collaboration and increased citations

- maximum visibility for your research: over $100 \mathrm{M}$ website views per year

At $\mathrm{BMC}$, research is always in progress.

Learn more biomedcentral.com/submissions 